\title{
Learning Styles and Academic Achievement among Medical Students at Ain Shams University: An Experience During COVID-19 Era
}

\author{
Hebat-Allah M.S .Gabal, Rasha S. Hussein
}

Department of Community, Environmental and Occupational Medicine, Faculty of Medicine, Ain Shams University.

\author{
Submission Date: 2020-01-10 Revision Date: 2020-03-07 Acceptance Date: 2020-03-07
}

\section{Abstract}

Background: During the COVID-19 era, the educational system was modified to include blended learning, using a multi-delivery mode to optimize outcome and have the best program delivery cost. Identifying students' learning styles (LS) is an important factor that contributes to scholastic accomplishment, resulting in a more satisfying learning. Objectives: To describe the learning style preferences among medical students at Ain Shams University; to investigate the associations between LS and academic achievement; and lastly, to determine whether preclinical and clinical students differ in their LS. Method: A cross-sectional study was conducted among a sample of 262 students using a self-administered questionnaire including socio-demographic data, academic achievement, and the Barsch Learning Styles Inventory. Results: The unimodal pattern of learning was the most prevalent style among surveyed students; about half of them used the unimodal visual style $(49.6 \%)$ while the trimodal style was the least $(0.8 \%)$. The most reported preferred educational materials include the private lessons summary $(64.8 \%)$ and the faculty books (61.4\%). The most frequently reported educational source was recorded audios $(82.4 \%)$. The LS preference did not differ between preclinical and clinical students. Conclusion and recommendations: The unimodal visual style was the predominant among surveyed students. Age, gender, academic year, study hours, and LS explain $59 \%$ of the variation in academic performance. Education and training in medicine need innovative ideas that match the students' styles. Educators should create a conducive atmosphere for learning and use methods of delivery that appeal to the senses using visual aids and materials to accommodate different learners.

Keywords: Learning Styles, Academic Achievement, Medical Students

Corresponding author: Hebat-Allah Mohammed Salah GabalＥmail: babosha2008@yahoo.com

\section{Introduction}

Learning is the inherent nature of a human; thus, it is an essential issue to address challenges in educational systems by discovering factors that affect the educational system. One of the fundamental factors that affect the educational process is the learning style, as it influences how learners master the goals and objectives of an educational program. ${ }^{1}$ The Learning Style was defined by Brown (2000) as "the manner by which individuals understand and process information in learning circumstances". The Learning Style preference indicates "the choice of one learning situation or 
condition over another". Additionally, Larkin and Budny (2005) mention that equivalent teaching and instructional modes are effective for some and ineffective for others, due to the different learning styles and one's biological and developmentally imposed combination of personal characteristics. ${ }^{2,3}$

Researchers have recognized three fundamental learning styles: visual, auditory, and kinesthetic. Visual learners process visual objects such as graphs, charts, and seeing information; auditory learners learn and understand through hearing and speaking, and kinesthetic learners prefer the hands-on tactile approach to learn new material. Identification and classification of students according to their dominating learning style can be done easily. However, one student can have a mix of learning styles, meaning that the same things can be learned through different ways ${ }^{4}$.

In Educational psychology, the learning style is the key construct, as it represents the learners' cognitive and emotional attitudes toward the educational programs; it also defines how learners deal with the learning circumstances. Any discrepancy between teaching methods and students' learning styles will have a negative impact on the educational process. Studies have shown that when the learning styles of students agree with the teaching approaches of teachers, this leads to more students' satisfaction and achievement, and more success in the educational process. ${ }^{5}$

With the paradigm shift in the medical education field from teacher-centered education to student-centered learning, the teachers' role has been altered from being a source of information to being a facilitator of learning. ${ }^{6}$ This shift fostered educators to demand the understanding of their students' learning styles to diversify the instructional modes and, therefore, the learning activities to satisfy various learners. ${ }^{7}$

Blended Learning (BL), which has become a fundamental method of education in the COVID-19 Era, integrates conventional face-to-face and online learning. BL is "based on the presumption that there were inherent benefits in face-to-face interaction in addition to recognizing that there were advantages to using on-line methods". The combination of in-class conventional methods plus technology components in learning will end up with a learning session that is more significant for the students. Moreover, the students can determine their targets, make decisions, and assess their advances when there is innovative technology during activities. ${ }^{8}$ Exploring the learning style perception among students will be beneficial because students can realize their own strengths and use their talents to improve their learning; moreover, teachers can determine and choose suitable teaching methodologies and appropriate learning opportunities. ${ }^{9}$

Previous studies have concentrated on characterizing the specific learning styles among medical field students, residents, and faculty members. ${ }^{10-13}$

The COVID-19 pandemic has posed many challenges for students and teachers, and unsurprisingly, student performance has suffered as a result. Indeed, the pandemic had a considerable impact on the delivery of medical education to both pre-clinical and clinical year students. The introduction of new educational methods (online webinars including key clinical conditions, case studies, didactic lectures, and examination questions) to medical students was accompanied by new assessment methods (online exams in the form of multiple choice questions with many 
universities adopting an open-book examination (OBE) approach). ${ }^{14,15}$ Some studies were done to address the impact of Blended Learning and remote teaching on the students' mental health and their awareness of electronic learning, but few studies have addressed how this change will affect the medical educational outcomes. $^{16-18}$

The students' learning style is a key factor and priority that needs to be addressed during this shift in the educational system to achieve student satisfaction and better academic outcomes. An efficient education system should be provided to enhance students' achievement by improving quality, access, and equity in education (especially in the field of medical education with its unique nature). Due to the scarcity of data on this topic during the current pandemic, this survey was conducted.

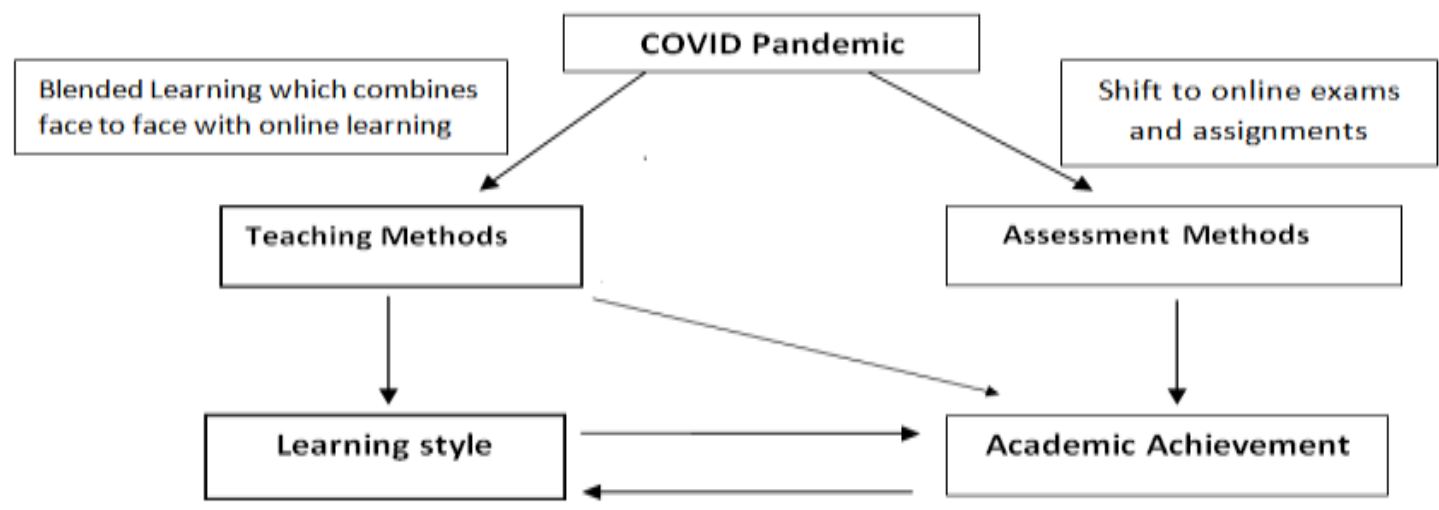

Figure 1: Theoretical Framework: the learning and teaching methods affect academic achievement directly and indirectly through the effect of the Learning Style

Table 1. Demographic and educational characteristics of the surveyed medical students $(\mathrm{N}=$ 262):

\begin{tabular}{|c|c|c|}
\hline Character & & $\mathbf{N}(\%)$ \\
\hline Age & Mean \pm SD (range) & $20.7 \pm 1.3(18-25)$ \\
\hline \multirow{2}{*}{ Gender } & Female & $148(56.5)$ \\
\hline & Male & $114(43.5)$ \\
\hline \multirow{2}{*}{ Nationality } & Egyptians & $236(90.1)$ \\
\hline & Other nationalities & $26(9.9)$ \\
\hline \multirow{2}{*}{ Academic year } & Preclinical & $195(74.4)$ \\
\hline & Clinical & $67(25.6)$ \\
\hline \multirow{2}{*}{ Educational System } & Mainstream & $250(95.4)$ \\
\hline & EMP & $12(4.6)$ \\
\hline \multirow{3}{*}{ Live With } & Family & $216(82.4)$ \\
\hline & Student hostel and friends & $30(11.5)$ \\
\hline & Alone & $16(6.1)$ \\
\hline Studying hours per day & Mean \pm SD (range) & $4.7 \pm 2.3(1-14)$ \\
\hline \multirow{3}{*}{$\begin{array}{l}\text { Preferred educational } \\
\text { materials** }\end{array}$} & Private lessons summary & $170(64.8)$ \\
\hline & Faculty books & $161(61.4)$ \\
\hline & Textbooks & $58(22.1)$ \\
\hline \multirow{2}{*}{ Educational sources** } & Recorded Audios & $216(82.4)$ \\
\hline & Recorded videos & $139(53.0)$ \\
\hline
\end{tabular}

The Egyptian Journal of Community Medicine

Vol. 39

No. 3

July

2021 
Lectures

$133(50.7)$

Private lessons

$114(43.5)$

Others *

$25(9.5)$

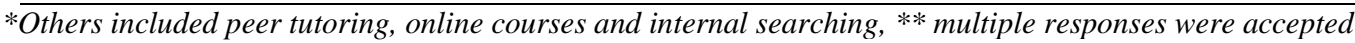

The main assumption of the current study builds on the effect of change in the educational system during the pandemic, involving both teaching and assessment methods that will impact academic achievement indirectly through the effect of learning style.

Based on the articulated objectives of the study, the following research questions were addressed in the study. What is the learning style preference among medical students at Ain Shams University? Is there an association between Learning Style and high academic achievement among study groups? Does the Learning Style differ between preclinical and clinical students?

Objectives: To describe the learning style preferences among medical students at Ain Shams University; to investigate the associations between learning styles and academic achievement; and to assess if preclinical and clinical students differed in their learning styles.

\section{Method}

Study design: A cross-sectional study was adopted to fulfill the purpose of the study.

Study setting and time: This study was performed among medical students at the Faculty of Medicine, Ain Shams University, for two months after the start of the new academic year 2020/2021. The Faculty of Medicine, Ain Shams University, was founded in 1947. It is considered one of the leading Egyptian public universities that contributes to the social and economic development of the nation. It was chosen because it is the third-oldest medical school in Egypt and enrolls a huge number of students. Ain shams University serves about 201505 students yearly in all faculties (from which about 7000 students are in the Faculty of Medicine). ${ }^{19}$

Students at the Faculty of Medicine, Ain Shams University, were illegible with exclusion of first-year students. At the Faculty of Medicine, Ain Shams University, the Bachelor of Medicine and Surgery program is divided into two major phases: a pre-clinical phase involving the first three years; and a clinical phase, involving the last three years in the classic discipline-based, and the last two years in the new fully integrated modular program. First-year students were excluded because being freshmen, they do not have a history of academic achievement within the faculty. ${ }^{19}$

A minimum sample size of 180 participants was calculated, using the PASS 11-program for sample size calculation, after reviewing results from the previous relevant study $^{\mathbf{1 3}}$, which showed that the auditory learning style had the least prevalence among other learning styles $(13.46 \%)$, considering a margin of error of $5 \%$ and a confidence level of $95 \%$.

Two hundred sixty-two medical students (262) accepted to participate in the study and were selected through a conveniencesampling technique.

Data collection tool: an anonymous online self-administrated questionnaire, delivered through different social media applications such as (What's App, and Facebook) plus official students' platforms. The questionnaire consisted of 3 sections: Socio-demographic data: (Age, Gender, and Nationality). Academic achievement: the students' academic achievement at the end of each year was measured using four degrees with the following codes: Accepted "1", Good "2", Very Good "3", and Excellent "4". The mean 
cumulative achievement score was derived by calculating the mean of the achievement degree of the student's previous academic years (summing up the achievement scores, then divided by the total number of educational years in the faculty for each student according to his/her academic year). The Barsch Learning Styles Inventory: it is one of the standardized tools for assessing learning styles which was developed by Jeffrey Barsch. This inventory consisted of 24 statements, and the responses were provided using a three-point Likert-type scale ( $5=$ often, $3=$ sometimes, and $1=$ seldom). Statements number $1,5,8,11,13,18,21$, and 24 represent the auditory learning style; statements number 4, 6, 9, 12, 15, 17, 19, and Table 2: Learning style preferences and their subcategories among the surveyed medical students $(N=262)$ :

\begin{tabular}{|c|c|c|}
\hline \multicolumn{2}{|c|}{ Character } & $\mathbf{N}(\%)$ \\
\hline \multirow{3}{*}{ Unimodal } & Visual & $130(49.6)$ \\
\hline & Auditory & 67 (25.6) \\
\hline & Kinesthetic & $15(5.7)$ \\
\hline \multirow{3}{*}{ Bimodal } & $\begin{array}{l}\text { Visual, auditory } \\
\text { (VA) }\end{array}$ & $27(10.3)$ \\
\hline & $\begin{array}{l}\text { Auditory, } \\
\text { Kinesthetic (AK) }\end{array}$ & $8(3.1)$ \\
\hline & $\begin{array}{l}\text { Visual, } \\
\text { Kinesthetic (VK) }\end{array}$ & $13(5.0)$ \\
\hline Trimodal & $\begin{array}{l}\text { Visual, auditory, } \\
\text { Kinesthetic } \\
\text { (VAK) }\end{array}$ & $2(0.8)$ \\
\hline
\end{tabular}

23 represent the tactile (kinesthetic) learning style; and statements number 2, 3, $7,10,14,16,20$, and 22 represent the visual-learning style. Three learning modes will be defined once the test is complete: either being unimodal (Visual, Auditory, or Tactile learning styles); bimodal (including two learning styles); or trimodal (including the three learning styles). The responses provide three sum scores (one for each modality-specific learning style) with a maximum sum score of 40 and a minimum score of 8 . The learning mode that received the highest total points would be the learning mode that the students preferred to use. The reported reliability measure using Cronbach's alpha was 0.62-0.81 The reasons underlying the choice of this questionnaire are because this questionnaire is one of the valid assessment tools and is related to DePorter \& Hernacki's (2009) theory in classifying the types of learning styles. ${ }^{20-23}$

Educational materials were added at the end of the questionnaire including the different learning styles and pros and cons for each.

A pilot study was performed to cover $10 \%$ of the sample. The purpose was to establish the

clarity and relevance of the tools. Besides, it helped to estimate the time required for filling the questionnaire. Some questions were modified, such as the question that asks about preferred educational materials. Also, a question was added to ask about student's nationality Pilot data was excluded from the results.

Data management and analysis: The data has been updated, coded, registered on a computer. The analysis was done using the SPSS package (version 25). For categorical variables, descriptive statistics were provided as frequencies and percentages, and as mean and standard deviation for continuous variables when normally distributed and when not normally distributed, as median and interquartile range (IQR). The mean academic achievement score was not normally distributed, so the Kruskal-Wallis test was performed to compare this parameter among different learning styles. Chi-square was used to test the association between students' preferred learning style and their gender, nationality, and daily study hours. Also, ANOVA test was used to examine the differences in studying hours per day among different learning styled students. Multiple linear regression was also used to identify the impact of different factors on 
the academic achievement. $\mathrm{P}$-value $\leq 0.05$ was considered significant.

\section{Ethical Considerations:}

Approval was taken from the ethical committee of the Faculty of Medicine, Ain Shams University, Egypt. Informed consent was taken from participants as the questionnaire started by asking the responders about their acceptance to participate in the study. Confidentiality was guaranteed through their anonymity.

\section{Results}

A total of 262 students $(43.4 \%$ males and $56.6 \%$ females) were enrolled in the study, with their mean age at $20.7 \pm 1.3$ years. $74.4 \%$ of them were from preclinical

Table 3: Relationship between academic achievement and learning style preference

\begin{tabular}{lccccc}
\hline \multicolumn{1}{c}{ Learning style preference } & $\begin{array}{c}\text { Visual } \\
\text { Median } \\
(\mathbf{I Q R})\end{array}$ & $\begin{array}{c}\text { Auditory } \\
\text { Median } \\
(\mathbf{I Q R})\end{array}$ & $\begin{array}{c}\text { Tactile } \\
\text { Median (IQR) }\end{array}$ & $\begin{array}{c}\text { Multi- } \\
\text { modal } \\
\text { Median } \\
\text { (IQR) }\end{array}$ & $\begin{array}{c}\text { Kruskal } \\
\text { Wallis Test (p } \\
\text { value) }\end{array}$ \\
\hline $\begin{array}{l}\text { Cumulative academic } \\
\text { achievement score }\end{array}$ & $3(2.5-4)$ & $3(2.33-3.67)$ & $3(2.5-4)$ & $3(2.5-4)$ & 0.67 \\
\hline $\begin{array}{l}\text { Cumulative academic } \\
\text { achievement score in } \\
\text { preclinical years }\end{array}$ & $3(2.5-4)$ & $3(2-3.67)$ & $3(2.67-3.33)$ & $3(2.5-4)$ & 0.84 \\
$\begin{array}{l}\text { Cumulative } \\
\text { achievement score in clinical } \\
\text { years }\end{array}$ & $3.67(3-4)$ & $3(2.47-3.71)$ & $2.83(2-4)$ & $3.67(3-4)$ & 0.33 \\
\hline
\end{tabular}

Table 4. Relationship between study hours and learning style preference by academic year:

\begin{tabular}{lccccc}
\hline \multirow{2}{*}{ Academic year } & \multicolumn{2}{c}{ unimodal/multimodal (studying Hours per day) } & \multirow{2}{*}{ p value* } \\
\cline { 2 - 5 } & $\begin{array}{c}\text { Visual } \\
\text { Mean } \pm \text { SD }\end{array}$ & $\begin{array}{c}\text { Auditory } \\
\text { Mean } \pm \text { SD }\end{array}$ & $\begin{array}{c}\text { Tactile } \\
\text { Mean } \pm \text { SD }\end{array}$ & $\begin{array}{c}\text { Multi-model } \\
\text { Mean } \pm \text { SD }\end{array}$ & \\
\hline Second year & $4.6 \pm 1.9$ & $5.5 \pm 2.5$ & $7.3 \pm 2.1$ & $4.4 \pm 1.8$ & $0.03^{* *}$ \\
Third year & $4.9 \pm 2.4$ & $4.0 \pm 2.1$ & $4.3 \pm 2.8$ & $5.8 \pm 3.0$ & 0.28 \\
Fourth year & $4.5 \pm 2.4$ & $3.6 \pm 1.3$ & $5.2 \pm 1.8$ & $4.3 \pm 2.2$ & 0.58 \\
Fifth year & $4.3 \pm 2.1$ & $2.7 \pm 1.2$ & $0.0 \pm 0.0$ & $8.0 \pm 8.5$ & 0.42 \\
\hline
\end{tabular}

*One Way ANOVA test (Bonferroni post hoc test), **p value $<0.05$

academic years and most of them $(90.1 \%)$

were Egyptians. The mean study hours were $4.7 \pm 2.3$ (1-14), the most reported preferred educational materials included private lessons summary $(64.8 \%)$ and faculty books (61.4\%). The most frequently reported educational source was recorded audios (82.4\%) followed by recorded videos (53\%) (Table 1). Regarding learning style preference, the unimodal pattern of learning was the most prevalent learning style (80.9\%) among the surveyed students; the visual learning style was the most prevalent unimodal learning style (49.6\%), while the kinesthetic learning style was the least $(5.7 \%)$. The trimodal style (VAK) (visual, aural, and kinesthetic) was the least prevalent mode $(0.8 \%)$ compared with the unimodal and bimodal styles (Table 2). Concerning the relationship between academic achievement and learning style preference among the study sample, results show that there were few differences regarding the mean cumulative achievement score among different learning styles preferences, and that these differences were not statistically significant $(\mathrm{p}>0.05)$. Also, no statistically significant difference was found between academic achievement and learning style among preclinical and clinical students (Table 3 ). 
By examining the relationship between learning style preference and studying hours among different academic years, a statistically significant association was found among second-year students as visual learning style students study less than auditory and tactile students (Table 4).
Studying the association between students' preferred learning style, and their gender, nationality, daily studying hours, and academic years, has revealed that the unimodal visual learning style is the most common style among the study sample: for males $(54.4 \%)$; for females $(56.6 \%)$; for Egyptians (50.4\%); for non-Egyptians

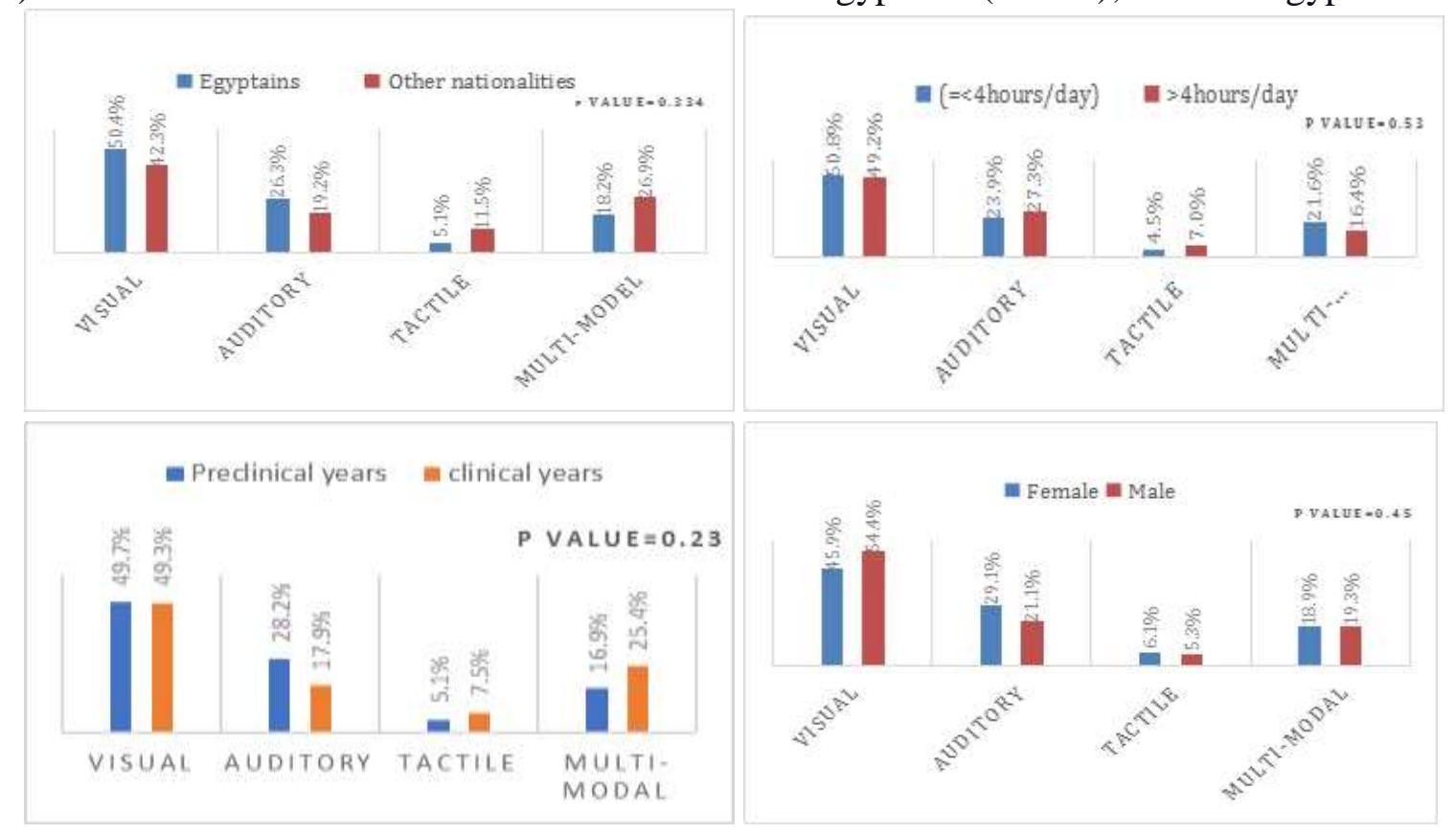

Figure2: Distribution of students' preferred learning style by gender, nationality, daily study hours and academic years.

$(42.3 \%)$; for students studying $\leq 4$ hours per day $(50.8 \%)$; for students studying $>4$ hours per day (49.2\%); for students at preclinical years $(49.7 \%)$; and for students at clinical years $(49.3 \%)$. There were minor differences between different categories in the learning styles' distribution. However, those differences were not statistically significant $(p>$ 0.05) (Figure 2).

Multiple linear regression analysis was done to explain and explore variables that might affect academic achievement among the study sample (depending on $\mathrm{R}^{2}$ ). Age, gender, academic year, study hours, and learning styles explain $59 \%$ of the variation in academic performance (R2 $=0.59, \mathrm{~F}=52.20, \mathrm{P}<0.001)($ Table 5).

\section{Discussion}

To the best of our knowledge, this study is the first that tackles learning style preference and its relationship with academic performance among medical students in Egypt. The COVID-19 pandemic has affected academic performance in varying degrees. ${ }^{18}$ The change in teaching and assessment methods during the COVID-19 era should match the students' learning styles to achieve more satisfied learning with better academic performance. The analysis of this study has revealed several interesting 
points. First, concerning the learning style preference among medical students, most of the students used the unimodal pattern of learning $(80.9 \%)$. The visual learning style was the most prevalent unimodal learning style, (49.6\%) while the kinesthetic learning style was the least (5.7\%). The trimodal style (VAK) (visual, aural, and kinesthetic) was the least prevalent mode $(0.8 \%)$, compared with unimodal and bimodal styles.

Prior research conducted by Atwa et al., 2016, used Barsch Learning Styles Inventory to assess the styles of learning among a sample of 455 students recruited from Ibn Sina National College for Medical Studies. The research showed that visual learning style was the most prevalent while

Table 5: Multiple linear regression model for factors associated with academic performance among medical students.

\begin{tabular}{|c|c|c|c|c|c|c|}
\hline Model ${ }^{\#}$ & $\beta$ & $\mathbf{t}$ & Sig. & F test & Model $\mathbf{R}^{2}$ & p value \\
\hline Age (increase) & 0.07 & 0.64 & 0.52 & \multirow{8}{*}{52.20} & \multirow{8}{*}{0.59} & \multirow{8}{*}{$<0.001$} \\
\hline Gender * & -0.21 & -1.066 & 0.29 & & & \\
\hline Study hours ** & 3.52 & 18.90 & $<0.001 *$ & & & \\
\hline Academic year**** & -0.16 & -0.530 & 0.60 & & & \\
\hline \multicolumn{4}{|l|}{ Learning style $^{4 * * * * *}$} & & & \\
\hline Visual & -0.11 & -0.26 & 0.80 & & & \\
\hline Auditory & -0.26 & -0.61 & 0.54 & & & \\
\hline Multimodal & 0.30 & 0.67 & 0.50 & & & \\
\hline
\end{tabular}

\#mean achievement score*Reference group is female, **Reference group studying hours less than 4, *Reference group preclinical years, *Reference group is tactile tri-modal was the least $(3 \%)$. The rest of the study population had two styles dominating the third one (bimodal VK, VA, or AK). ${ }^{24}$ Similarly, a study that addressed learning style preferences among Indonesian freshmen using the Barsch Learning Styles Inventory, found that most students preferred visual learning $(61.7 \%)$, and that $8.2 \%$ of the students were bimodal. The similarity may be attributed to the used tool and the study population being conducted among medical students. ${ }^{25}$

The current study findings were in congruence with a cross-sectional study held among 171 final year Physical Therapy students using the VARK questionnaire (Visual, Aural, Read \& Write \& kinesthetic), which revealed that the preferred learning style was unimodal (31.6\%), followed by bimodal (31\%). ${ }^{26}$ However, the results were different from the study done by Javadinia et al., 2010; the aforementioned study found that the predominant learning style among Iranian students was the auditory one $(48.6 \%)^{27}$. Also, the results contrasted with studies done by Nuzhat et al., 2011 and Baykan \& Naçar, 2007; these studies found that multimodal learning styles among medical students were the dominant ones $(73 \%$ and $64 \%$, respectively $)^{28,29}$. Another survey was conducted among 142 first-year Bachelor of Medicine, Surgery, and Dental Surgery students using the VARK questionnaire; it revealed a diversity in learning styles among undergraduate students, but that most of them were multimodal $(53.52 \%)$. The most common multimodal type was bimodal $(26.06 \%) .{ }^{30}$ Also, Butt et al., 2020 conducted a crosssectional study among 593 individuals including students, house officers, and demonstrators of dental colleges, using the VARK questionnaire. The study revealed that $83 \%$ of individuals used the unimodal pattern of learning; the Kinesthetic and Aural modes of learning were used by
Vol. 39
July 
$24.5 \%$ and $25.3 \%$ of individuals, respectively; while the Visual mode was used by $15.5 \%$ of individuals. Furthermore, the multimodal mode represents only $1.5 \%{ }^{31}$

Also, the study results differed from two studies that were performed among Egyptian nursing students. The first study involved 641 students from the Faculty of Nursing, Assiut University, and concluded that the highest percentage of students preferred the unimodal learning styles (kinesthetic/tactile learning style, followed by visual learning style and then auditory learning style). ${ }^{32}$ Another descriptive study conducted at the Faculty of Nursing, Benha University, on a sample of 376 nursing students at $4^{\text {th }}$ academic year using the students' Learning Styles Questionnaire, found that most of them reported that they preferred the kinesthetic/tactile learning style, followed by the auditory preference, and then by the visual preference. ${ }^{33}$

Hamidah and Kusuma, 2020, also conducted a study to analyze trends in student learning styles during the COVID19 pandemic period using the student learning style questionnaire and found that the learning styles of students were diverse but that students tend to prefer the auditory learning styles $(50 \%)$ while $42.11 \%$ of the students were visual learners and $7.89 \%$ were kinesthetic learners. ${ }^{34}$ Differences in the findings between the previously cited researches may be due to differences in tools used for assessment, faculty experience, and methods of teaching that vary according to the academic year and specialty.

The second interesting point was that univariate analysis revealed that the learning style does not have a significant influence on academic achievement. Similarly, Almigbal, 2015 conducted a cross-sectional study among 600 medical students in the Kingdom of Saudi Arabia using VARK questionnaire and found that learning style preferences were not linked to academic achievement. ${ }^{35}$ Also, Imtiaz et al., 2019, and Khanal et al., 2019, concluded in their studies that academic performance was not affected by learning styles $(\mathrm{P}>0.05){ }^{26,30}$ Shenwai and Patil, 2017, in their study involving 150 firstyear medical students, concluded that there were no significant difference in the exam grades of unimodal, bimodal \& multimodal learners. ${ }^{36}$ In addition, Ojeh et al., 2017 performed a study among preclinical students who were engaged in diverse courses in the first three years of the undergraduate at the Faculty of Medical Sciences, and pointed out that learning style preferences were not associated with academic grades. ${ }^{37}$

Pello'on et al., 2013, who worked on the relationship between students learning styles using Kolb's learning style and grade performance in ophthalmology course (5th-year medical students), found that the medical students preferred the visuallearning style, which worked independently on the academic performance of the students. ${ }^{38}$ Another study was conducted at The University of Lahore on 109 nursing students and found a significant correlation between learning and academic achievement in nursing students. ${ }^{39}$ Differences between studies can be explained by the variation in the effectiveness of learning methods and correlation with learning styles.

The third important point involving factors that may be associated with learning style preference is that the univariate analysis revealed that gender, nationality, daily study hours, and being in preclinical or clinical years were not significantly associated with learning style.

Similarly, multiple other studies have showed no association between gender and 
learning style ${ }^{24,27,29,37}$ However, genderdifference in learning style was reported by Almigbal, 2015, Shenwai and Patil, 2017, and Khanal et al.,2019 ${ }^{35,36,30}$

Application of integrated modular programs with an ascertain on advanced learning and assessment methods including problem-based learning, small group discussions with continuous assessments, and integration of different teaching methods, mostly explains the similarity between preclinical and clinical students in their learning style. Samarakoon et al., 2013, pointed out that among a sample of medical undergraduates of the University of Colombo, most of the first year and final year students used multimodal styles of learning, and that the learning styles did not vary significantly over the undergraduate years of medical education. ${ }^{6}$ Similarly, a cross-sectional study in Nigeria was conducted among 206 medical students to determine the change in learning styles preferences over years of education (preclinical versus clinical), found that multimodal learning style predominated the preference. Both studies contradict the current findings concerning predominant learning style; however, both studies agree on the final relation between learning style and being in preclinical or clinical years. $^{40}$

The multiple linear regression analysis has revealed that age, gender, academic year, study hours, and learning styles explain $59 \%$ of the variation in academic performance $\quad\left(\mathrm{R}^{2}=0.59, \quad \mathrm{~F}=52.20\right.$, $\mathrm{P}<0.001)$. Many factors like age, gender, and study skills, have been identified as good predictors of students' academic performance. Academic performance impacted many by students' studying hours; a significant positive association was found between the student academic achievement and study hours being $>4$ hours per day ( $\beta=3.25,95 \%$ CI 3.15-3.89).
By contrast, a study that addressed factors potentially influencing academic performance among medical students in Saudi Arabia, found that age, gender, academic year, and studying more than 4 hours per day did not affect academic achievement $^{41}$.

Identifying the effective modes of learning is the first step toward changing the teaching strategy. Students' awareness of their own learning styles will help them to adopt suitable studying methods to maximize their learning abilities. Also, faculties should tailor teaching methods to match students' learning preferences.

Conclusion: The unimodal pattern of learning was the most prevalent learning style $(80.9 \%)$ among the surveyed medical students; the visual learning style was the most prevalent unimodal learning style (49.6\%), while the kinesthetic learning style was the least $(5.7 \%)$. The trimodal style (VAK) was the least prevalent mode $(0.8 \%)$, compared with unimodal and bimodal styles. The learning style preference did not differ between preclinical and clinical students. Age, gender, academic year, study hours, and learning styles explain $59 \%$ of the variation in academic performance.

Recommendations: Knowing learning styles can help students to be engaged with various teaching and learning activities and can promote the individual's professional lifelong learning. During the current COVID-19 era, education and training in medicine need innovative ideas that match students' styles, resulting in an enjoyable and effective learning. Educators should create a conducive atmosphere for learning and use methods of delivery that appeal to the senses using concrete objects, visual aids, and materials to accommodate different learner.

Study Limitations: There is a limited power of cross-sectional design to 
determine the causal effect; longitudinal studies should consider looking at the effect of adjusting the teaching style by medical educators to match the learning style preference of medical students and its effect on achievement. Furthermore, the current study addresses medical students in one of the famous faculties in the capital city; further studies should be conducted to involve students from different universities and compare learning styles between students from different faculties.

Consent for publication: "Not applicable"

Funding: There has been no financial support for this work.

Acknowledgment: The authors would like to express their great appreciation to participants who generously shared their time and agreed to participate in this study.

Disclosure Statement: The authors state that they have no competing interests.

Data Availability Statement: The datasets generated and analyzed during the current study are available from the corresponding author on request.

\section{References}

1. Rassool G.H, Rawaf S. The influence of learning style preference on undergraduate nursing students on educational outcomes in substance use education. Nurse Education in Practice, 2008;8 (5), 306-14.

2. Brown D.H. Principles of Language Learning and Teaching, (4th ed). New York: Longman, Inc, 2008.

3. Larkin T.L. \& Budny D. Learning styles in the classroom: Approaches to enhanced student motivation and learning. In ITHET 6th Annual International Conference, 2005. Retrieved from http://fie.engrng.pitt.edu/ithet2005/papers/200 3.pdf

4. Abante M, Almendral B, Manansala J, Mañibo J. Learning styles and factors affecting the learning of general engineering students. International Journal of Academic Research in Progressive Education and Development, 2014;3(1):16-27.
5. Hallin K. Nursing students at a universityA study about learning style preferences. Nurse education today,2014; 34(12), 1443-9. DOI: $10.1016 /$ j.nedt.2014.04.001

6. Samarakoon L, Fernando T, Rodrigo C and Rajapakse S. Learning styles and approaches to learning among medical undergraduates and postgraduates. BMC Medical Education, 2013;13:42-5.

7. Sinnerton T, Leonard L, Rogers K. Using learning style preferences to enhance the education and training of allied health professionals. The International Journal of Allied Health Sciences and Practice, 2014;12(1):1-5.

8. Shamsuddin N, Kaur J. Students' learning style and its effect on blended learning, does it matter? International Journal of Evaluation and Research in Education, 2020;9(1),195-202. DOI: 10.11591/ijere. v9i1.20422

9. ALQahtani, D. A., \& Al-Gahtani, S. M. Assessing learning styles of Saudi dental students using Kolb's Learning Style Inventory. Journal of dental education,2014;78(6), 927-33. $\quad$ PMID: 24882779.

10. Fredette J, O'Brien C, Poole C, Nomura J. Do emergency medicine residents and faculty have similar learning styles when assessed with the Kolb learning style assessment tool? Del Med J. 2015 Apr;87(4):109-12.

11. Mammen, J.M. V, Fischer D.R., Anderson A., et al. Learning styles vary among general surgery residents: analysis of 12 Years of data. J Surg Educ,2017;64(6), 386-9. DOI: 10.1016/j.jsurg.2007.08.005.

12. Samarakoon L., Fernando T., \& Rodrigo C. Learning styles and approaches to learning among medical undergraduates and postgraduates. BMC Med Educ,2013;13(1),42. DOI:10.1186/1472-6920-13-42.

13. Joy N \& Basiru A. Preference of Learning Styles and its Relationship with Academic Performance among Junior Secondary School Students in Dutse Local Government Area, Jigawa State, Nigeria. International Journal of Education and Practice,2016;4(3),127-33. DOI: $\quad 10.18488 \quad$ /journal.61/2016.4.3/ 61.3.127.133 
14. Sani I, Hamza Y, Chedid Y, Amalendran J, Hamza N. Understanding the consequence of COVID-19 on undergraduate medical education: Medical students' perspective Annals of Medicine and Surgery,2020;58,1179 https://doi.org /10.1016/j.amsu.2020.08.045 15. Giordano L, Cipollaro L, Migliorini F, Maffulli N. Impact of Covid-19 on undergraduate and residency training, The Surgeon, 2020; S1479-666X(20)30169-4.DOI: 10.1016/j.surge.2020.09.014

16. Alsoufi A, Alsuyihili A, Msherghi A, Elhadi A, Atiyah H, Ashini A, et al. Impact of the COVID-19 pandemic on medical education: Medical students' knowledge, attitudes, and practices regarding electronic learning. PLoS ONE,2020;15(11): e0242905 https://doi.org/10.1371 /journal. pone.0242905

17. Khattar A, Jain P, Quadri S. Effects of the Disastrous Pandemic COVID 19 on Learning Styles, Activities and Mental Health of Young Indian Students - A Machine Learning Approach. Proceedings of the International Conference on Intelligent Computing and Control Systems (ICICCS 2020).

18. Mahdy MA. The Impact of COVID-19 Pandemic on the Academic Performance of Veterinary Medical Students. Front. Vet. Sci,2020;7:594261. doi: 10.3389/fvets.2020.594261

19. Ain Shams University Official home pages,

http://med.asu.edu.eg/home/en/http://www.asu .edu.eg/

20. Barsch Learning Styles Inventory. (n.d). Retrieved from http://lvillinois.org/Barsh\%20 Learning\%20Styles.pdf.

21. Doyran, Feyza. The effects of perceiving teacher non-verbal behaviors, teacher behaviors and preferred learning styles on English proficiency. (Doctoral Dissertation). Middle East Technical University, Ankara, Turkey,2020.

22. Khan S.A, Arif M.H and Yousuf M.I.A. Study of Relationship between Learning Preferences and Academic Achievement. Bulletin of Education and Research, 2019; 41(1), 17-32.

23. DePorter, B. \& Hernacki, M. (2009). Quantum learning. Bandung: Kaifa.
24. Atwa.H, Abozeid E, Fouad S. How Do Medical Students Learn at Ibn Sina National College for Medical Studies in Jeddah, KSA? Assessment of Student's Learning Styles. Education in Medicine Journal 2016; 8(1): 2530. DOI: 10.5959/eimj. v8i1.408

25. Manipuspika, Y. M. Learning Styles of Indonesian EFL Students: Culture and Learning. Arab World English Journal,2020; 11 (1) 91-102. DOI:10.24093/awej/vol11no1.8 26. Imtiaz I, Nisa MU, Hina S, Akram MJ, Kareem S, Ahmed N, tabbasum S. Association of Learning Style \& Stress with Academic Achievement Among Physical Therapy Students. RCRS. 2019; 7(2):54-7. DOI: 10.5455/JRCRS. 2019070204

27. Javadinia S, Sharifzadeh G, Abedini M, Khalesi M, Erfanian M. Learning styles of medical students in birjand university of medical sciences according to VARK model. Iranian Journal of Medical Education. 2010;11(2):141-7.

28. Nuzhat A, Salem R, Mohammed S. Learning style preferences of medical students. International Journal of Medical Education. 2011; 2:70-3.

29. Baykan Z, Naçar M. Learning styles of firstyear medical students attending Erciyes University in Kayseri, Turkey. Advances Physiology Education. 2007; 31:158-60.

30. Khanal L, Giri J, Shah S, Koirala S, Rimal $\mathrm{J}$. Influence of learning-style preferences in academic performance in the subject of human anatomy: an institution-based study among preclinical medical students. Advances in Medical Education and Practice, 2019;10: 343-55

31. Butt F, Naz A, Darvesh SA, Hussain M, Shaikh MS, Faisal. Learning strategies used by dental students and dentists using the vark questionnaire. Professional Med J 2020; 27(5):1065-9. DOI: $10.29309 / \mathrm{TPMJ} / 2020$. 27.05 .4317

32. Saaid B., Yousef H, Morsy S.' Faculty of Nursing Students Learning Styles and its Impact on their Academic Achievement at Assiut University', Assiut Scientific Nursing Journal, 2016;4(7), 13-27. DOI: 10.21608/asnj.2016.58625 
33. Mohamed AA, Morsi MM. Learning Styles, Learning Approaches, Academic Achievement Factors, and Self Efficacy among Nursing Students. International Journal of Novel Research in Healthcare and Nursing,2019:6(1), 818-30. Available at: www.noveltyjournals.com

34. Hamidah and Kusuma J W. Analysis of student learning styles and geometry thinking skills: During the covid-19 pandemic, J. Phys: Conf. Ser, $1657 \quad$ (2020) 012036. doi:10.1088/1742-6596/1657/1/012036

35. Almigbal TH. Relationship between the learning style preferences of medical students and academic achievement. Saudi medical journal, 2015; 36(3):349.

36. Shenwai MR, Patil KB. Assessment of learning style preferences and their influence on gender \& academic performance among first year medical undergraduate students. Natl J Integr Res Med, 2017;8 (1):109-116.

37. Ojeh N, Sobers-Grannum N, Gaur U, Udupa A, Majumder A. Learning style preferences: a study of pre-clinical medical students in Barbados. J Adv Med Educ Prof. 2017;5(4):185-94.

38. Pello'on M. Nome S and Ara'an A. Relationship between learning style and academic performance of fifth graders enrollment in the medical course. Revista Brasileira De Oftalmologia,2013; 72(3): 181-4 39. Nosheen $N$ and Hussain $M$. The Association Between Learning Style, Learning Strategies with Academic Performance Among Nursing Students. Journal of Health, Medicine and Nursing, 2020. ISSN 2422-8419.

40. Salihu AS, Ibrahim A, Owolabi SD, Adamou N, Usman UM, Bello MM, et al. Learning style preferences of medical students in Kano, Northwestern, Nigeria. Niger J Basic Clin Sci 2020; 17:46-9.

41. Al Shawwa L, Abulaban AA, Abulaban AA, Merdad A, Baghlaf S, Algethami A, AbuShanab J, Balkhoyor A. Factors potentially influencing academic performance among medical students. Adv Med Educ Pract. 2015 Jan 29; 6:65-75. doi: 10.2147/AMEP.S69304. PMID: 25674033; PMCID: PMC4321417. 